\title{
Besprochene Arbeiten.
}

Barton, G. A.

Two New Hebrew Weights . I I49

Berger, Ph.

Inscrr. du temple d'Esmoun . . 50

Inscr. néo-punique de Tatahouine $6_{3}$

Quelques inscrr. néo-puniques . . 64

Inscr. grecque de Pouzzoles .. 89

Nouv. inscr. du temple d'Echmoun 154

Nouv. inscr. phénicienne de Saìda I 54

Inscr. funéraire de Carthage . . 174

Vase de plomb découv. à Carthage 176

BLAKE, FR. R.

Siloam Inscription...... I9I

BrünNow, R. u. v. DomaszewSKI, A.

Die Provincia Arabia . . 265, 402

Bruston, C.

Études phéniciennes. . . 153, 188

Cagnat, R.

Inscr. grecque de Pouzzoles . . 89

СНABOT, J.-B.

Inscriptions palmyréniennes. . . 80

Chapot, V.

Antiquités de la Syrie du Nord. 323

Clay, Alb. T.

Business Documents. . . . . . 203

Collection dE CLERCQ.

Catalogue, tome IV ..... 318

Clermont-Ganneau, $\mathrm{CH}$.

Recueil d'archéologie orientale.

Tome IV. S 20: p. 85. - $27: 85$. -

S 28:8I. $-\$ 30: 85 .-\$ 42: 93 .-$

$\$ 45: 89 .-\$ 66: 86$.

Tome V. $\$ 3: 84 .-\$ 7: 55 .-\$ 8$ : 79. $-\$ 15: 77 .-\$ 16: 62 .-\$ 18: 87$.

- \$ 19: 55. - \$\$20, 22: $86 .-\$ 23$ :

68. $-\$ 26: 70 .-\$ 28: 86 .-\$ 29:$

56. $-\$ 30: 82 .-\$ 32: 87 .-\$ 33: 77$.

- S 41: 50. - \$48: 153. - S 51: I74.

- S 53: 198. - S 56: 154. - S 57: 165.

Tome VI. S 9: $167 .-\$ 13: 191 .-\$ 14$ :

249. $-\$ 18: 224,237 .-\$ 19: 154$.

S 22: 199. - S 22a: 163. - S 23: 199.

- \$ 24: 344. $-\$ 25: 210 .-\$ 27: 182$.

- S 29: 336. - \$ 32: 140. $-\$ 34: 375$.

- \$ 39: 154. - S 45: 187. $-\$ 46:$ I70.
Seite

Clermont-Ganneau, $\mathrm{Ch}$.

Tome VII. S I : $277 .-S 18: 375 .-$

S 21: 335 .

Monuments palmyréniens . . . 79

CoOK, ST. A.

Hebrew Inscr. from Gezer . . 145

Egyptian Slab (CIS II, 143) . . 249

Nabataean Graffiti. . . . . 268

COOKE, G. A.

Phoen. Inscr. of Bostān esh-Shẹh I 53

Aramaic Papyrus . . . . . 224

COWLEY, A.

Egyptian Aram. Documents . . . 223

Cumont, Fr.

Le dieu Orotalt d'Hérodote . . 118

Inscription gréco-araméenne . 249

DeiAtrre, A.-L.

Carthage ........ 171

Derenbourg, $H$.

Nouv. textes yéménites . . . 102

Le culte de la déesse al.'Ouzzâ. 379

Une inscription yéménite. . . 379

Nouveaux envois du Yémen . . 382

Premier supplément ..... 387

Dickson, GL.

The Tomb of Nicanor. . . 198

DUSSAUD, $\mathbf{R}$.

Inscription d'en-Nemâra . . . 34

Rapport sur une mission . . . 4I

Chronologie des rois de Sidon . 159

Les Arabes en Syrie . . 346, 375

Dussaud, R. et Macler, Fr.

Mission dans les régions déser-

tiques de la Syrie 251, 326, 345, 375

EutiNg, J.

Un Papyrus égypto-araméen . . 210

FISCHER, A.

Zur Siloahinschrift . . . 71, 191

FRAENKEL, S.

Remarques....... 80

Semit.-griech. Eigennamen . . $33^{8}$

Glaser, Ed.

Suwấ und Al.'Uzzâ . . . . 379

Eine südarabische Inschrift . . . 386

Aus meinem Inschriftenwerk 394,396 


\section{Glaser Ed.}

Altjemenische Nachrichten . . 394 Gray, G. B.

The Names in the Papyrus. . 224 Gregorio, G. DE.

Iscrizione fenicia.... . 60

GRIFFIVI, E.

Nuove iscrizioni sabaiche . . 392

GrimME, $\mathrm{H}$.

Rešafim . . . . . . . 153

Genesis des sem. Alphabets . . 37 I

Internes aus der min. Religion . 394

Südarabische Tempelstrafgesetze 394

HALÉVY, J.

L'alphabet safaitique . . . . 24

Les inscriptions proto-arabes . . 26

Nouv. Inscriptions de Sidon . . 50

L'origine de l'Alphabet . . . . I2I

Les inscriptions de Bodaśtoret . I53

Inscription punique . . . . . 185

Le nom du Dieu NIN.IB . . 203

Papyrus égypto-araméen . . . 210

Document judéo-araméen . . 224

Documents judéo-araméens . . 237

L'Inscription d'En-Némara . . 375

Inscription du Djebel Djihaf . . $3^{80}$

HartmanN, M.

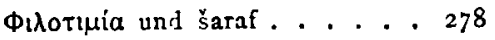

Zur Inschrift von Namāra . . 375

Südarabisches . . . . . . . . 394

Heuzey, L.

Archéologie orientale . . . 55, 8I

Hoffmann, $G$.

Inschriften aus dem Es̆muntempel 50

JAHN, G.

Die Mesha-Inschrift . . . . 150

JALABERT, L.

Triade Héliopolitaine . . . . 325

Jaussen, A. et Savignac, R.

Inscrr. nabat. de Pétra . . . . 73

Jaussen, A., Savignac, R., Viveent, $H$.

'Abdeh . . . . . . 263, 337

KAUTzsCH, EM.

Ein althebräisches Siegel . . I40

Konig, ED.

Die Mesa-Inschrift . . . . 150

Kokowzow, $P$.

Palmyrenische Inschriften . . . 169
Lagrange, M.-J.

Seite

Inscrr. trouvées par Macridy-Bey 50

Inscrr. du temple d'Echmoun . . 153

Explor. archéologique au Négeb 263

Deux bustes palmyréniens . . 312

I.ANDAT, W. VON.

Eshmuntempel bei Sidon. . . 153

I.ivy, Isin.

Malcandre . . . . . . . 164

LiTrMANN, EN.

Safa-Inschriften . . . . . . 24

Semitic Inscriptions . . 257, 306, 345

Inscriptıons from Si" . . 258, 336

Princeton Univ. Expedition . 336, 346

Erwälnung eines Perserkrieges . 353

Thamudenische Inschriften . . 354

L'origine de l'alphabet libyen . 363

LitTmann, EN. und Krencker, D.

Aksumexpedition . . . . 396

Löwy. A.

Echtheit der moab. Inschrift . 150

Macalister, A. St.

The Ossuary of Nicrnor. . . I 88

MACRIDY-Bey, Th.

Le teinple d'Echmoun . . 50, 153

Milne, J. G.

Greek Inscriptions . . . . 338

MüLLER, D. H.

Inscr. from Jabal Jehaf . . . 380

Südarabische Inschriften . . $383 \mathrm{f}$.

Nöldeke, TH.

Die sem. Buchstabennamen . 125

Peiser, F, E.

Die Inschrift von En-Nemâra . 375

Pilcher, E. J.

Inscription of Bod-'Aštart . . I53

Porter, H.

Another Phoenician Inscription . 154

Praetorius, Fr.

Zur Gesch. des griech. Alphabets 119

Zur Inschrift des Mēša . . . I5 I

Zur Ešmūñāzār-Inschrift . . . I63

Phönizische Namen auf של ש 170

Zum südsemitischen Alphabet 366

Ursprung des kanaan. Alphabets $37 \mathrm{I}$

Sabäisch T"̈s ,wer immer" . 394

Sabäisches und Äthiopisches . . 395

Sabäisch "sie selbst" 396 
Seite

Prentice, WM. K.

Djebel Shêkh Berekât . . . $8 \mathrm{I}$

Ronzevalie, S.

Notes d'épigr. palmyrénienne . . 77

Un bas-relief de Homs . . . 83

Jupiter Heliopolitanus . . . . 87

Un bas-relief trouvé à Émèse . 310

Monuments de Gebeil-Byblos . . 324

Inscr. bilingue de Deir el-Qaláa 325

Rouvier, LE DR.

Nouv. inscr. phén. de Saìda . I 54

Savignac, $R$.

Ossuaires juifs . . . . . I99

Inscrr. nabatéennes du Hauran . 257

Glanures épigraphiques . . . 334

Savignac, R. et Abel, M.

Inscriptions nabatéennes . . . 26I

Inscriptions grecques et latines - 335

SAYCE, A. H.

Note [on Aram. Papyrus] . . 224

Sobernhety, M.

Palmyrenische Inschriften . . 276

Spiegelberg, W.

Zu dem Straljb. aram. Papyrus, 210
SPOFR, H. H.

Palmyrene Inscriptions . . . 3I3

Palmyrene Tesserae . . . . 319

Notes on some Palmyr. Tesserae 321

STADE, B.

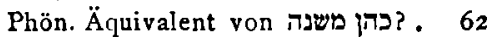

Stevenson, J. $\mathrm{H}$.

Assyr. and Babyl. Contracts . . 200 Torrik, CH. C.

Phoen. Royal Inscription . . . 50

Semitic Epigraphical Notes . 145, 148

Bod-'Aštart Inscriptions . . . I53

A new Inscription . . . . 154

Two Letters from Prof. Porter . 155

Four Palmyrene Epitaphs . . 316

VINCENT, $H$.

Nouvelle intaille israélite . . 70

Nouvel ossuaire juif . . . . 72

VoGüE, MARQUIS DE.

Inscr, aram. trouvée en Égypte . 221 WEBER, $O$.

Südarabische Altertumskunde 98 , 101 WINCKLER, $\mathrm{H}$.

Zu semitischen Inschriften .. . 6

Inschrift von Ešmuntempel : 154

Sabäisch båal . . . . 396 